\title{
Bacterial Communities of Ballan Wrasse (Labrus bergylta) Eggs at a Commercial Marine Hatchery
}

\author{
Aileen Bone ${ }^{1} \cdot$ Michaël Bekaert $^{1} \cdot$ Athina Papadopoulou $^{1} \cdot$ Stuart McMillan $^{1} \cdot$ Alexandra Adams $^{1} \cdot$ Andrew Davie $^{1}$. \\ Andrew P. Desbois ${ }^{1}$ (1)
}

Received: 12 April 2020 / Accepted: 6 November 2020 / Published online: 23 November 2020

(c) The Author(s) 2020

\begin{abstract}
Ballan wrasse (Labrus bergylta, Ascanius 1767) are cleaner fish cultured in northern Europe to remove sea lice from farmed Atlantic salmon (Salmo salar, Linnaeus 1758). Despite increasing appreciation for the importance of the microbiota on the phenotypes of vertebrates including teleosts, the microbiota of wrasse eggs has yet to be described. Therefore, the aim of this present study was to describe the bacterial component of the microbiota of ballan wrasse eggs shortly after spawning and at 5 days, once the eggs had undergone a routine incubation protocol that included surface disinfection steps in a common holding tank. Triplicate egg samples were collected from each of three spawning tanks and analysis of $16 S$ rRNA gene sequences revealed that $88.6 \%$ of reads could be identified to 186 taxonomic families. At Day 0 , reads corresponding to members of the Vibrionaceae, Colwelliaceae and Rubritaleaceae families were detected at greatest relative abundances. Bacterial communities of eggs varied more greatly between tanks than between samples deriving from the same tank. At Day 5, there was a consistent reduction in 16S rRNA gene sequence richness across the tanks. Even though the eggs from the different tanks were incubated in a common holding tank, the bacterial communities of the eggs from the different tanks had diverged to become increasingly dissimilar. This suggests that the disinfection and incubation exerted differential effects of the microbiota of the eggs from each tank and that the influence of the tank water on the composition of the egg microbiota was lower than expected. This first comprehensive description of the ballan wrasse egg bacterial community is an initial step to understand the role and function of the microbiota on the phenotype of this fish. In future, mass DNA sequencing methods may be applied in hatcheries to screen for pathogens and as a tool to assess the health status of eggs.
\end{abstract}

\section{Introduction}

Ballan wrasse (Labrus bergylta Ascanius 1767) are cleaner fish recognised as an established and important biological component of sea lice control in Atlantic salmon (Salmo salar Linnaeus, 1758) farming in northern Europe [1-3] The cleaner fish remove sea lice from infested salmon and recent efforts have reduced reliance on wild capture, with more

Aileen Bone and Michaël Bekaert have contributed equally to this work.

Electronic supplementary material The online version of this article (https://doi.org/10.1007/s00284-020-02286-8) contains supplementary material, which is available to authorized users.

Andrew P. Desbois

andrew.desbois@stir.ac.uk

1 Institute of Aquaculture, Faculty of Natural Sciences, University of Stirling, Stirling FK9 4LA, UK than half of demand for cleaner fish now delivered from farmed origins $[4,5]$.

Health management and infection control are of central importance in aquaculture. During ballan wrasse production, eggs are exposed to broad-spectrum disinfectants, such as formalin and bronopol, in an effort to inactivate potential pathogens attached to or within the egg that may hinder or prevent development and hatching and may impact the health of larvae thereafter [6, 7]. Disinfection is effective for improving egg survival but indiscriminate and it likely alters the entire microbial community (i.e. microbiota) of the egg [8]. However, it is increasingly apparent that the microbiota of vertebrates, including teleosts, can profoundly affect many aspects of an organism's development, health status, metabolic capability, behaviour, and other phenotypes [9-11]. Greater understanding of the microbiota of fish eggs and its effects on various traits is required. Ultimately, the ability to manipulate the microbiota may deliver early-life stage improvements in survival and development, as well as 
benefits at later life stages deriving from phenotypes such as enhanced immune protection and better feed conversion $[8,9,12,13]$.

After hatching, bacteria are introduced into the sterile gastrointestinal tract of the developing larva from the water and through consumption of egg chorion material, and this contributes to the establishment and development of the internal microbiota $[14,15]$. Some maternal-derived bacteria can even exert beneficial effects on egg development by preventing the attachment of potential pathogens $[13,16]$. Despite this, little is known of the composition of the microbiota of marine fish eggs, including those of ballan wrasse; however, recent advances in DNA sequencing technology permit detection and taxonomic classification of almost all bacteria in a sample, and not just those that can be cultured, through sequencing of partial segments of the $16 \mathrm{~S}$ ribosomal RNA (rRNA) gene. Such methodologies provide novel insights into the dynamic flux of microbiota communities that can be utilised in a range of medical and agricultural applications, including disease prevention, diagnosis and treatment $[10,17,18]$. Still, these techniques have yet to be widely applied in the context of aquaculture hatchery management where microbial community management has been a long-standing challenge $[8,12]$.

Therefore, the aim of this present study was to apply a mass DNA sequencing approach to characterise the bacterial component of the microbiota of ballan wrasse eggs during commercial production, in samples collected shortly after spawning and at 5 days, once these had undergone a routine incubation protocol that included surface disinfection steps.

\section{Materials \& Methods}

\section{Collection of Egg Samples}

Ballan wrasse eggs were collected within $24 \mathrm{~h}$ of spawning ('Day 0') from each of three spawning mats from three spawning tanks at a commercial ballan wrasse hatchery in Machrihanish, Scotland, giving nine samples in total. Each broodstock tank was $7 \mathrm{~m}^{3}$ and these were connected as banks of five to a common recirculation system (TMC 10000 recirculation system; Tropical Marine Centre, Chorleywood, UK), operating at a 2-h turnover rate. The recirculation system was equipped with protein skimmer, mechanical filtration $(1000 \mu \mathrm{m})$, biofilters, ultraviolet disinfection and thermal control to maintain a constant water temperature of $12{ }^{\circ} \mathrm{C}$. Study Tanks 1 and 2 were connected via a common recirculation unit, while study Tank 3 was part of another unit. Typically, in a given day the mats from the same tank will derive from a single pair mating [19]. Each sample consisted $c a .1 \mathrm{~g}$ of eggs that were scraped carefully into a universal bottle, frozen immediately in a dry shipper and then stored at $-70{ }^{\circ} \mathrm{C}$. Each mat and the rest of the eggs thereon underwent surface disinfection by bathing in formalin (100 ppm; Sigma Aldrich, Gillingham, UK) for $1 \mathrm{~h}$ followed immediately by bathing in bronopol (100 ppm; Pyceze, Novartis Animal Vaccines Ltd, Litlington, UK) for $1 \mathrm{~h}$, and then the mats and remaining eggs were incubated at $12-13{ }^{\circ} \mathrm{C}$ in a common holding tank connected to a third independent recirculation system (TMC 5000 recirculation system; Tropical Marine Centre). On Day 2 and Day 4, the mats were removed from the common holding tank and the surface disinfection steps were repeated, before returning the mats to the same holding tank. At Day 5, eggs were collected from each mat as described above (a further nine samples, giving 18 in total). The egg volumes did not change noticeably (by visual inspection under a light microscope) during the 5-day incubation. A schematic diagram of the experimental design is shown in Fig. 1.

\section{DNA Extraction}

DNA was extracted from $c a .200 \mathrm{mg}$ wet weight of each frozen egg sample (which included the gum layer) using the QIAamp Fast DNA Stool Mini Kit according to the manufacturer's instructions (QIAamp Fast DNA Stool Mini Handbook, 2014; available at: www.qiagen.com). Each sample was defrosted and then $1 \mathrm{~mL}$ of InhibitEX buffer and at least five sterile glass beads was added before placing in a bead beater for $2 \mathrm{~min}$. At the end of the extraction procedure, the DNA in each sample was eluted in $200 \mu \mathrm{L}$ ATE buffer. A buffers-only control was performed and included in all following procedures.

\section{Quantification of dsDNA}

Total dsDNA in each sample was quantified by fluorimetry (Qubit 2.0; Life Technologies, Paisley, UK) using broad range (BR) reagents. To each of $190.5-\mathrm{mL}$ microcentrifuge tubes (Axygen; Tewksbury, MA, USA) was added $95 \mu \mathrm{L}$ of 1:200 BR dye:buffer mastermix and $4 \mu \mathrm{L}$ tris-EDTA buffer (pH 8) with $1 \mu \mathrm{L}$ of test sample (for the 18 experimental samples) or $1 \mu \mathrm{L}$ control solution (for the buffers-only control); two standards were prepared (95 $\mu \mathrm{L}$ of 1:200 BR dye:buffer mastermix and $5 \mu \mathrm{L}$ of either BR standard) for calibration. The samples were incubated at room temperature for $5 \mathrm{~min}$ before being read. Hereafter, high sensitivity reagents only were used to quantify total dsDNA in samples.

\section{Preparation of 16S rRNA Libraries with Adaptors}

The $16 S$ rRNA libraries were prepared for sequencing on a MiSeq platform according to manufacturer's instructions [20] using primers (Eurofins, Brussels, Belgium) designed to amplify the $\mathrm{V} 3-\mathrm{V} 4$ hypervariable region of 
Fig. 1 Schematic representation of the experimental design. At Day 0 (i.e. within $24 \mathrm{~h}$ of spawning), ballan wrasse eggs were collected from each of three spawning mats from three separate spawning tanks ( $1 \mathrm{~g}$ of eggs from each mat). The ten spawning tanks at the site are connected as two banks of five to separate recirculation systems (RAS), with Tanks 1 and 2 sharing the same RAS. The eggs remaining on each mat underwent surface disinfection by bathing in formalin (100 ppm) for $1 \mathrm{~h}$ and then bronopol $(100 \mathrm{ppm})$ for $1 \mathrm{~h}$, before the mats were transferred to a common holding tank connected to a third RAS. On Day 2 and Day 4 , the surface disinfection steps were repeated, and the mats were returned to the common holding tank. At Day 5, a further $1 \mathrm{~g}$ of eggs were collected from each mat

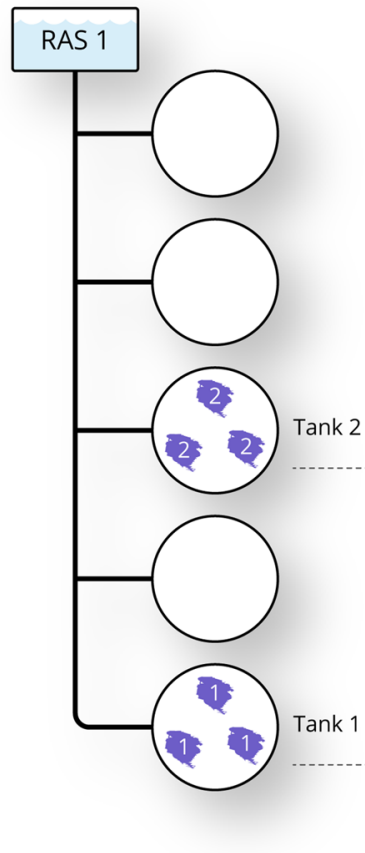

Day 0

Sample triplicate spawning mats from Tanks 1, 2 and 3

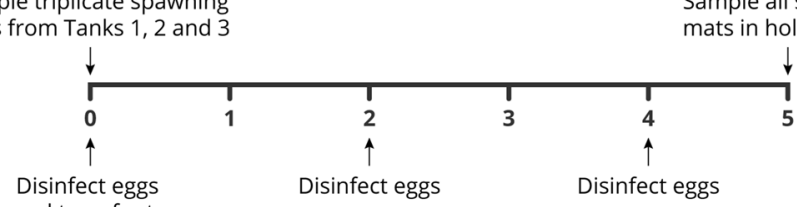

the holding ta

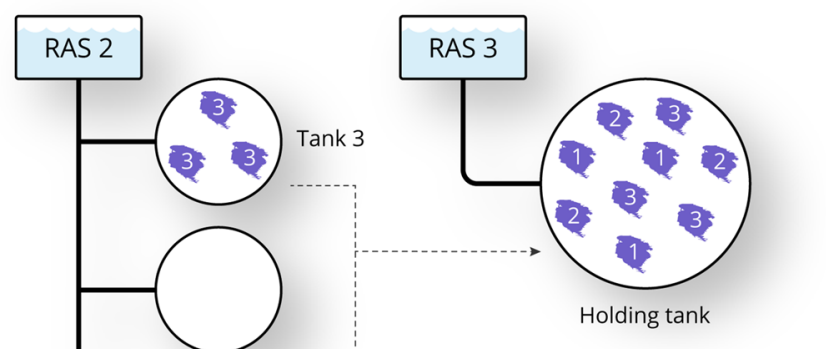

Day 5

Sample all spawning mats in holding tank the 16S rRNA gene, with some minor modifications to the protocol. Notably, Q5 Hot Start High-Fidelity DNA Polymerase (New England Biolabs, Ipswich, UK) was used, and when amplifying $16 \mathrm{~S}$ rRNA sequences from each sample the reaction was divided equally between three tubes to reduce PCR bias during the 25-cycle run and then re-combined for clean up using AxyPrep magnetic beads (Axygen). A no template control (NTC) was included.

\section{Gel Electrophoresis}

Following clean up, the concentration of dsDNA was determined as above. Approximately $10 \mathrm{ng}$ of total PCR product was run through a $1 \%$ agarose gel $(0.5 \times \mathrm{TAE}$, $0.08 \mu \mathrm{g} / \mathrm{mL}$ ethidium bromide) to confirm expected amplicon size (530 bp) and the presence of a single product band. A 100-bp DNA ladder was used as a molecular mass marker. The NTC and a non-purified but amplified sample were used as controls. The gel was run at $10 \mathrm{~V} / \mathrm{cm}$ until the ladder had migrated and separated sufficiently.

\section{Addition of Indices and Sequencing Primer}

The Nextera XT Index kit (Illumina) was used to uniquely index each of the PCR amplified samples, following the Nextera Low Plex Pooling Guidelines [21]. The resultant indexed amplicons were cleaned up as above and the final sample was resuspended in $27.5 \mu \mathrm{L}$ of $10 \mathrm{mM}$ Tris (pH 8.0). Purified PCR products were quantified and run through a $1 \%$ agarose gel as above to confirm expected amplicon size (601 bp) and the presence of a single product band.

\section{Sequencing on MiSeq Platform}

Each sample was adjusted to $20 \mathrm{nM}$ in $10 \mathrm{mM}$ Tris (pH 8.0) and then pooled in equal volumes to give a final library sample. The dsDNA concentration in this library was determined as above, and prepared for sequencing according to the standard protocol [20]. The library (final concentration of $4 \mathrm{pM}$ and including an $8 \%$ phiX spike-in) was run on a MiSeq sequencer (250 base paired-end reads; 500 -cycle v2 reagent kit). 


\section{Analysis and Processing of Sequencing Data}

The mothur v1.42.0 [22] was used to analyse the sequencing data following the MiSeq standard operation procedure of Schloss et al. [23]. Briefly, all paired-end sequences were combined, sequence reads were aligned and taxonomically classified with the SILVA database release 132 [24], and chimeric sequences removed by applying VSEARCH v2.9.1 [25]. Unclassified sequences were clustered to operational taxonomic units (OTUs) at a distance cut-off level of 3\%. OTUs with no match in the SILVA database were grouped together as "unclassified". Taxonomic assignments determined at the family level were used in subsequent analyses (Supplementary Table S1), although some OTUs that did not match at family level were reported at a higher taxonomic level (i.e. order). The raw sequences are available at EBI European Nucleotide Archive database under Project PRJEB30278.

\section{Statistics}

OTU abundances were normalised using variance-stabilising transformations and Binomial-Beta models [26]. Diversity indices, $\alpha$ (richness), $\gamma$ (total diversity) and $\beta$ (overlap; $[\gamma / \alpha]-1)$, were calculated with the R/vegan package v2.5-3 [27] in R [28] and R/vegan v3.5.1 was used for the permutational multivariate analysis of variance (adonis function), and the ordination of the redundancy analysis ( $r d a$ function after log-relative transformation). Correlation assessments were calculated with Kendall's tau model [29] and $P$-values when comparing for significant differences between the Day 0 and Day 5 samples after log-relative transformation were adjusted for multiple comparisons according to Benjamini and Hochberg [30]. Evaluation of richness variation was performed using a unilateral Welch's two sample t-test [31].

\section{Results}

The $16 S$ rRNA libraries prepared from the ballan wrasse egg samples generated 14,571,037 paired-end reads $(809,502 \pm 94,024$ per egg sample; mean \pm standard deviation), excluding the 17,326 reads from the buffers-only control. A summary of the sequencing statistics is presented in Supplementary Table S2. After filtering for quality, correct amplification fragment length and chimeric sequences, 9,768,510 paired-end reads remained. Of these, $88.6 \%$ of reads were identified to 186 taxonomic families (Table 1), while the remaining $11.4 \%$ of sequences corresponded to 55 OTUs classified at the taxonomic family level $(\gamma$-index $=241)$ but that lack formal family names.
Table 1 Alignment of all filtered $16 S$ rRNA reads to different taxonomic levels in libraries prepared from 18 ballan wrasse egg samples collected before disinfection (Day 0) and after disinfection and incubation (Day 5)

\begin{tabular}{lccl}
\hline Taxon & OTUs & Number (classified) & $\begin{array}{l}\text { Aligned } \\
\text { reads } \\
(\%)\end{array}$ \\
\hline Kingdom & 1 & 1 & 100 \\
Phylum & 28 & 27 & 98.90 \\
Class & 54 & 45 & 98.36 \\
Order & 143 & 120 & 91.44 \\
Family & 241 & 186 & 88.64 \\
Genus & 494 & 319 & 59.89 \\
\hline
\end{tabular}

In total, $88.6 \%$ of reads corresponded to 241 operational taxonomic units (OTUs) which included 186 taxonomic families with formal names

To minimise information loss while permitting meaningful interpretation of results, we focused our analyses on family level OTUs.

At Day 0, 223 families (and OTUs at family level) were detected with members of the Colwelliaceae (gamma-proteobacteria), Vibrionaceae (gamma-proteobacteria) and Rubritaleaceae (BV4 phylum) present at greatest relative abundance, corresponding to $23.6 \pm 5.9 \%, 20.8 \pm 5.6 \%$ and $15.8 \pm 1.3 \%$ of total filtered reads, respectively (Fig. 2). Bacterial communities of the egg samples varied more between the tanks ( $\beta$-index $=0.71$; Adonis test: $\mathrm{R}^{2}=0.86, P<0.001$ ) than between samples deriving from within the same tank ( $\beta$-indices: Tank $1=0.30$; Tank $2=0.31$; Tank $3=0.30$; Adonis test, $\left.\mathrm{R}^{2}=0.03, P=0.311\right)$.

At Day 5 (after routine incubation with surface disinfection steps in the common holding tanks), the bacterial communities varied more between the tanks from where they originally derived ( $\beta$-index $=0.71$; Adonis test: $\mathrm{R}^{2}=0.77$, $P<0.001)$ than between samples deriving from the same tank ( $\beta$-indices: Tank $1=0.32$; Tank $2=0.27$; Tank $3=0.30$; Adonis test: $\mathrm{R}^{2}=0.08, P=0.045$ ). Interestingly, the bacterial communities deriving from the different tanks changed significantly between Day 0 and Day 5 (Adonis test: $\mathrm{R}^{2}=0.22$, $P<0.001)$ and, unexpectedly, these bacterial communities had diverged from each other to become more dissimilar (Welch's two sample t-test: Tank $1, P<0.001$; Tank 2, $P=0.012$; tank 3, $P=0.017$ ). At Day 5, the bacterial communities of eggs collected from Tank 1 were dominated by Colwelliaceae, Shewanellaceae (gamma-proteobacteria) and Saccharospirillaceae (gamma-proteobacteria), while Tank 2 and Tank 3 communities were dominated by Vibrionaceae, Rubritaleaceae and Pseudoalteramonadaceae (gammaproteobacteria) (Fig. 2). Sampling time (Day 0 vs. Day 5) had a smaller influence on bacterial community composition (Adonis test: $\mathrm{R}^{2}=0.22, P<0.001$ ) than the tank from 


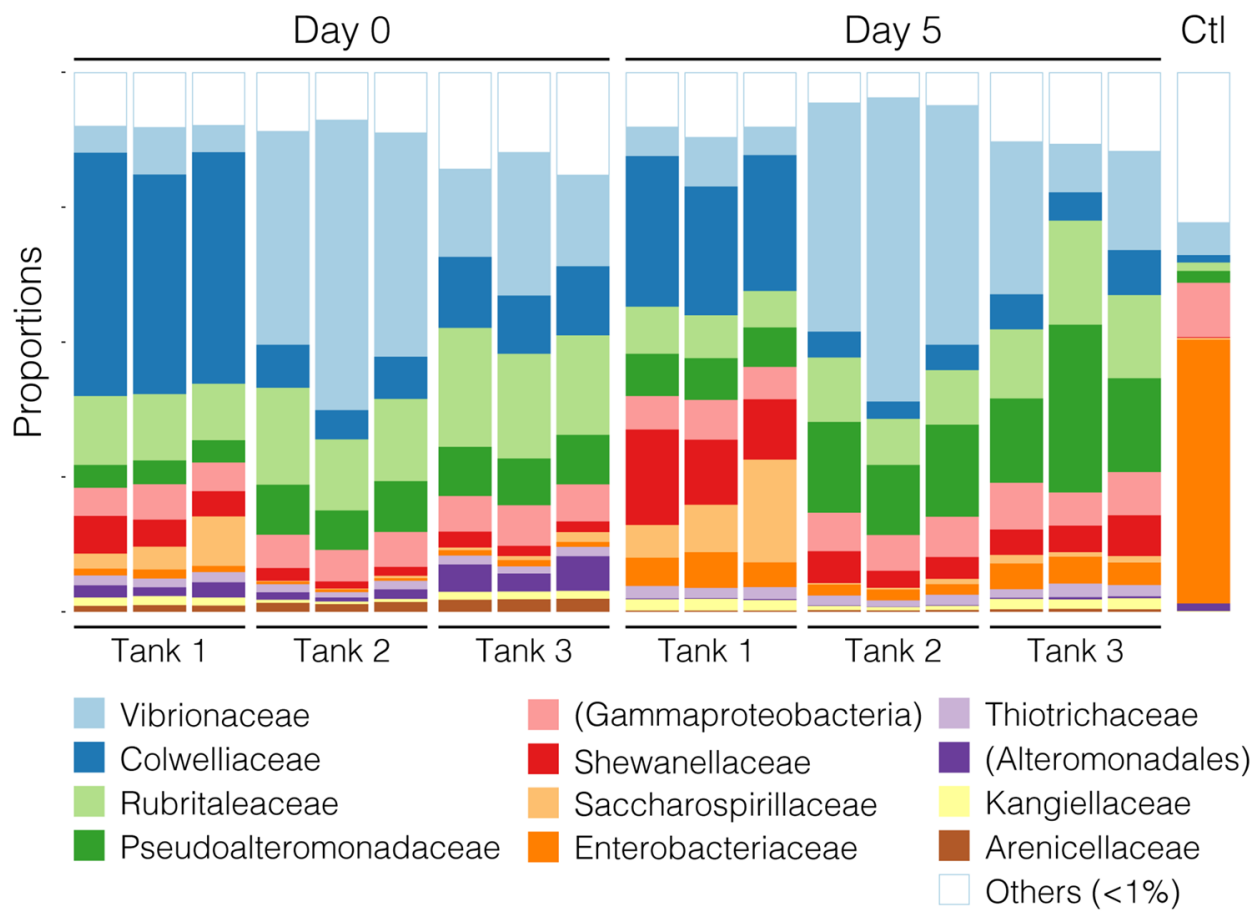

Fig. 2 Stacked bar chart of relative composition of bacterial taxonomic families in the triplicate egg samples collected from each of three spawning tanks as determined by relative abundance of $16 \mathrm{~S}$ $r R N A$ reads. After spawning (Day 0), the variation in relative composition of the bacterial communities was smaller between the samples collected from the same tank than between samples collected from different tanks. At Day 5, again, the variation in relative composi- tion of the bacterial communities was smaller between the samples collected from the same tank than between samples collected from different tanks; however, the bacterial communities from the different tanks had diverged to be even more distinct from each other. A buffers-only control (Ctl) sample was included. Names in brackets indicate unassigned family members belonging to the named class or order
A

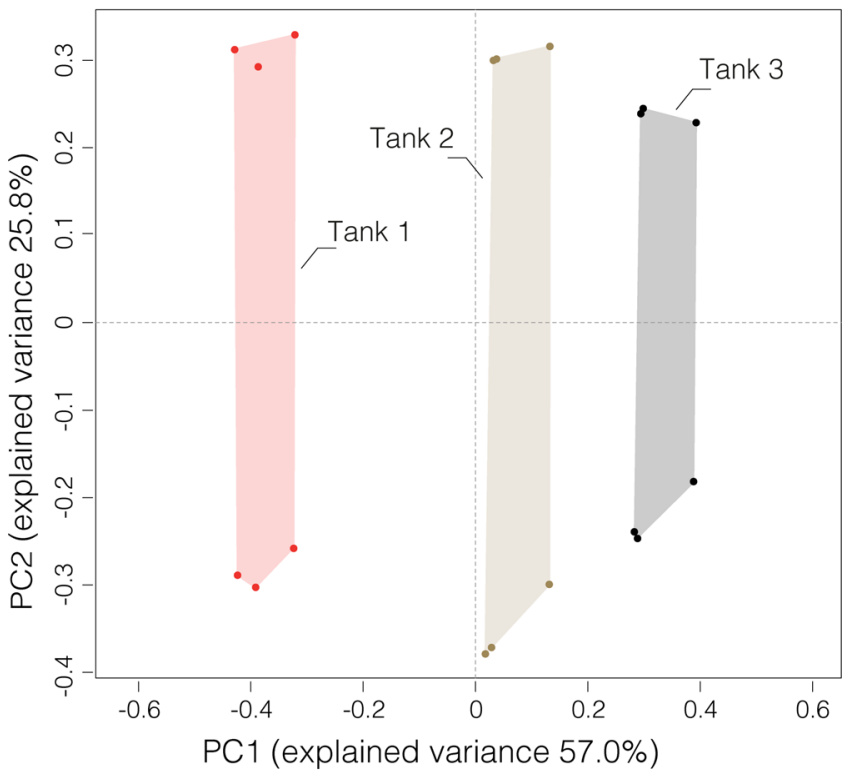

Fig. 3 Ordination result of redundancy analysis of relative compositions of bacterial communities in triplicate egg samples collected from each of three tanks as determined by relative abundance of $16 S r R N A$ reads with data grouped by tank (a) and sample time (b),
B

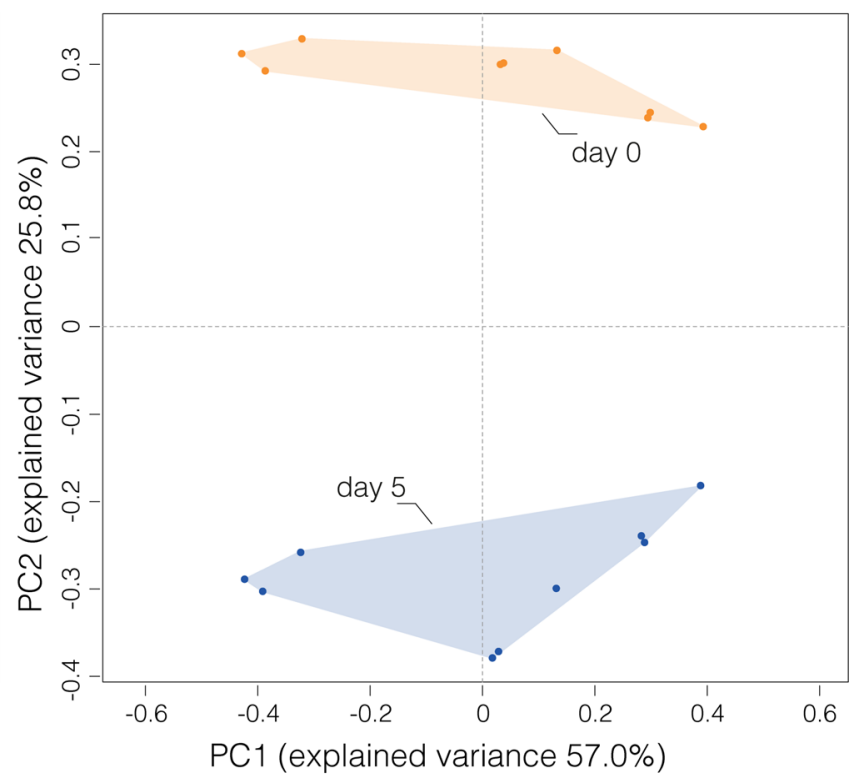

showing that sampling time (Day 0 vs. Day 5) had a greater effect on bacterial community composition than tank from which the samples were derived initially 
which the samples were derived initially (Fig. 3; Adonis test: $\left.\mathrm{R}^{2}=0.64, P<0.001\right)$, and these changes were relatively consistent across the tanks ( $\beta$-indices: Tank $1=0.58$; Tank $2=0.70$; Tank $3=0.64)$. Moreover, there was an overall reduction in bacterial community richness between Day 0 $(\gamma$-index $=223)$ and Day $5(\gamma$-index $=166)$, and this observation was consistent between the tanks (mean $\gamma$-indices: Tank $1=165 \rightarrow 140$; Tank $2=163 \rightarrow 103$; Tank $3=184 \rightarrow 136$ ). Only 18 families (of 166 in total) were present at Day 5 that were not detected at Day 0, but all of these were at $<1 \%$ relative abundance and these may have been introduced from the bacterial community present in the common holding tank water. Notably, 75 families present at Day 0 were not detected at Day 5.

With respect to the taxonomic families underlying the observed changes in bacterial community compositions, overall, between Day 0 and Day 5 there was a significant positive correlation in the relative abundance of members of the Thiotrichaceae (gamma-proteobacteria), while there was a significant negative correlation in the relative abundance of members of the Kangiellaceae (gamma-proteobacteria)
(Fig. 4). Various other taxonomic families at lower relative abundance $(<1 \%)$ also showed significant positive or negative correlations with time across the tanks (Fig. 4). A closer examination of the bacterial communities derived from each tank revealed differing and even contrasting trends in changes of relative abundances of the families. For example, the relative abundance of Vibrionaceae in bacterial communities deriving from Tank 1 showed a significant positive correlation between Day 0 and Day 5; however, members of this family showed a significant negative correlation in samples deriving from Tank 2 , while they showed no significant change in relative abundance in Tank 3 (Fig. 4). In bacterial communities deriving from Tank 1 , the relative abundance of Arenicellaceae and Saccharospirillaceae showed a significant negative correlation between Day 0 and Day 5 , while in bacterial communities deriving from Tank 2 the Colwelliaceae and Saccharospirillaceae showed a significant positive correlation during this time (Fig. 4). Within the tanks, there were significant positive or negative correlations with time for various taxonomic families present at lower relative abundance $(<1 \%)$.

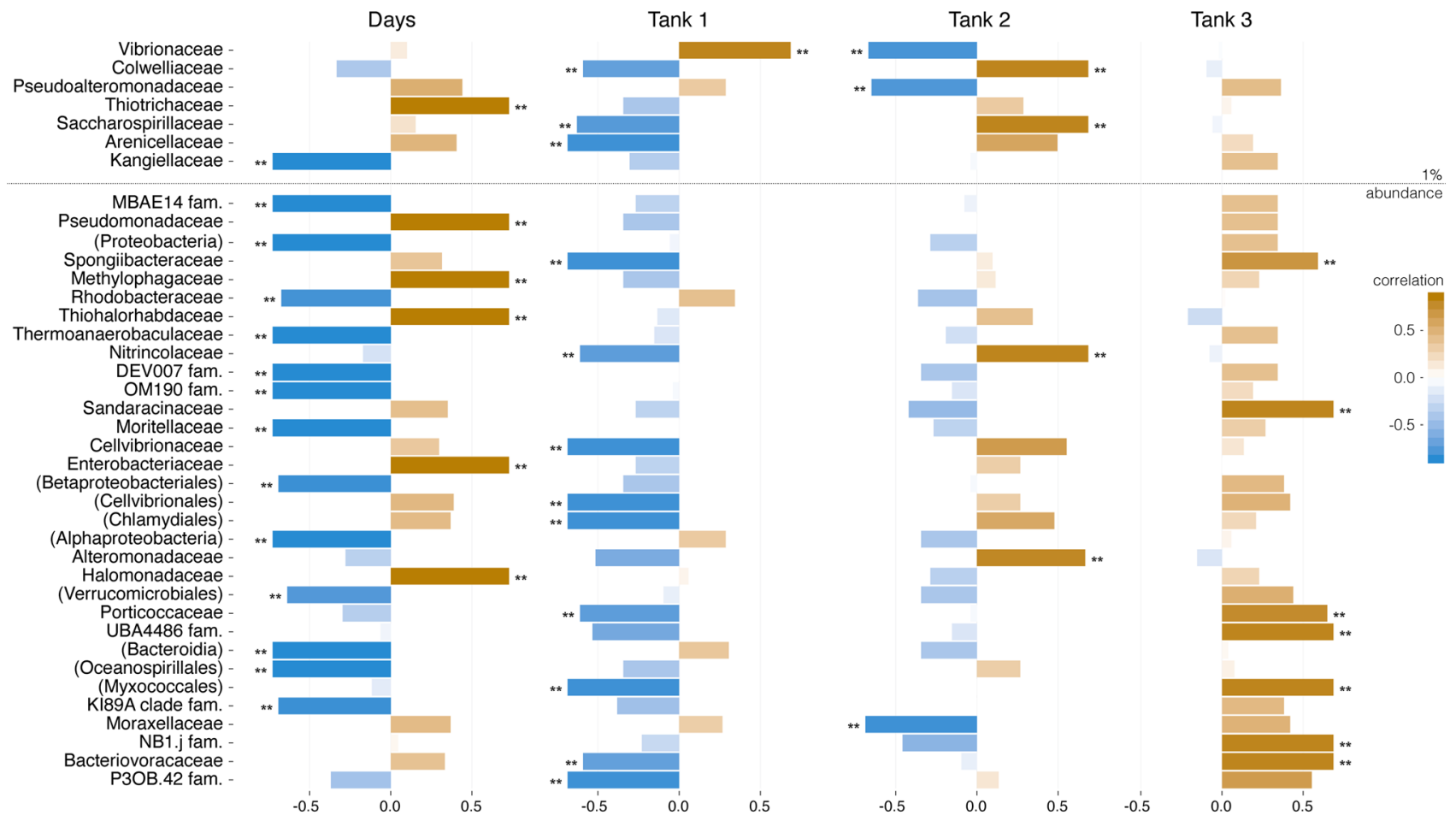

Fig. 4 Bar chart to show correlations between changes in the relative abundance of $16 \mathrm{~S} r R N A$ reads corresponding to bacterial taxonomic families shortly after spawning (Day 0) and after incubation (Day 5) across all egg samples ('Days') and for samples derived from each of the three tanks ('Tank 1', 'Tank 2' and 'Tank 3'). In the summative data, there was significant positive correlation in the abundance of members of the Thiotrichaceae between Day 0 and Day 5, while there was a significant negative correlation in the abundance of members of the Kangiellaceae. Nevertheless, differing and sometimes contrasting trends in relative abundances of families in the bacterial communities with time were detected between tanks, for example, the relative abundances of Vibrionaceae in samples from Tank 1 showed a significant positive correlation with time, while members of this family showed a significant negative correlation with time in Tank 2. Note that families are listed from most to least abundant and the dotted line indicates a $1 \%$ relative abundance threshold. Names in brackets indicate unassigned family members belonging to the named class or order 
Finally, the raw read data were searched to identify sequences corresponding to the presence of three pathogens known to cause disease problems in the ballan wrasse hatchery and that could be present in or on the eggs, specifically Aeromonas salmonicida (typical and atypical subspecies), Aliivibrio salmonicida and Vibrio splendidus. The raw reads were searched because the database used did not allow for species level resolution. Across the 18 egg samples, no reads were detected that corresponded to Aliivibrio salmonicida, only 22 (of 9,768,510) reads corresponded to Aeromonas salmonicida, and just 201 reads corresponded to V. splendidus. Sequences corresponding to Aeromonas salmonicida and $V$. splendidus were detected in egg samples from each of the three tanks at Day 0, but at Day 5 Aeromonas salmonicida was detected only in Tank 1 , while $V$. splendidus was only detected in Tank 2 and Tank 3 (Table 2). In general, there was relatively little variation in read abundances between the replicates deriving from each of the separate tanks (Table 2).

\section{Discussion}

The increasing appreciation for the beneficial properties conferred on vertebrates by the microbiota, including roles in development, health status, immunity, metabolic capability and nutrition [9, 10, 32], has led to studies that describe the microbiota of teleost fish species at different body sites and life stages [9, 32-34]. However, far less attention has been paid to the composition of the bacterial communities of marine fish eggs [9, 12, 35], including ballan wrasse, which is cultured to remove sea lice parasites from Atlantic salmon [4]. Given that bacteria from the water and the egg itself are incorporated during the establishment of the microbiota of the developing fish larva $[35,36]$, certainly the composition of the early egg microbiota warrants closer scrutiny. Various environmental parameters (e.g. diet, water temperature, salinity and presence of antimicrobial agents) and host factors (e.g. species, sex, genetics, developmental stage, age) are known to influence the composition and structure of the fish microbiota [11, 13, 32, 33, 37-39], but few studies have examined changes that occur following incubation protocols in hatcheries, which include surface disinfection steps. Therefore, the aim of this present study was to describe the bacterial component of the microbiota of ballan wrasse eggs shortly after spawning and once these had undergone a 5-day incubation in a common holding tank according to the protocols at a commercial hatchery. To this end, triplicate egg samples were collected from three spawning tanks and the $16 S$ rRNA sequences in the DNA extracted from the eggs were analysed on an Illumina MiSeq platform.

Incubation at the hatchery for 5 days, which included surface disinfection with formalin and bronopol, led to a

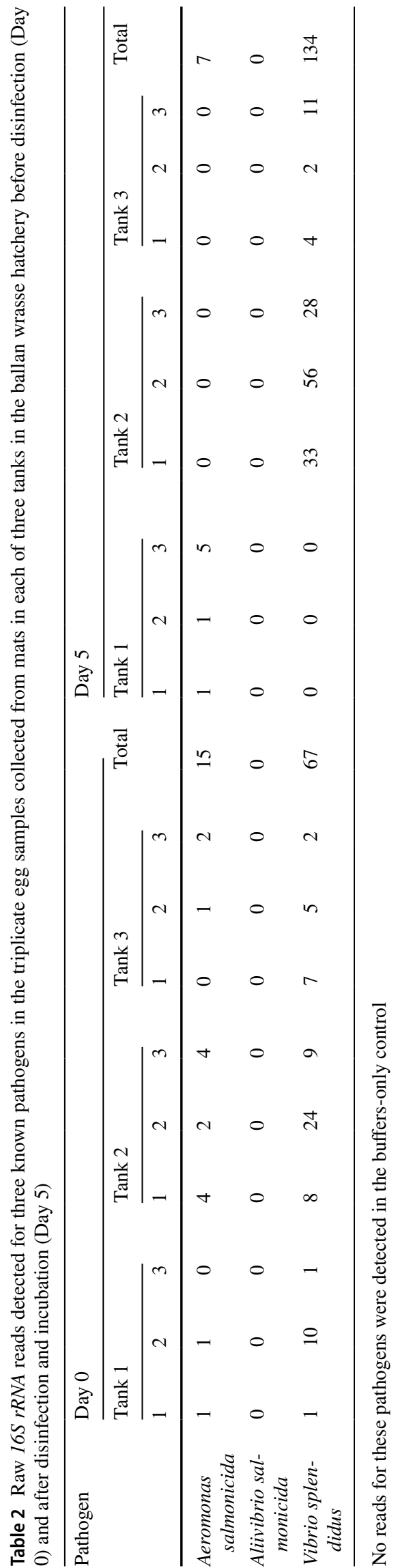


reduction in overall richness of the bacterial community associated with the eggs. Still, in general, the bacterial communities remained relatively unchanged between Day 0 and Day 5 in that most of the taxonomic families present shortly after spawning were also detected at Day 5 (148 of 223 families [i.e. 66.4\%], with only 18 families [i.e. 8.1\%] present at Day 5 that were not detected at Day 0). Indeed, families of gamma-proteobacteria, such as Vibrionaceae and Collwelliaceae, dominated the bacterial communities at Day 0 and Day 5 in this first description of the bacterial communities associated with ballan wrasse eggs. A predominance of members of the proteobacteria in the microbiota of the ballan wrasse eggs is consistent with other studies of marine hatchery fish eggs, skin and water bacterial communities [9, $14,35,36]$.

The microbiota of eggs from different mats within the same tank were relatively similar at Day 0 , which was expected because the egg samples are replicates that had been exposed to the same bacterial community in the water and were derived from the same single pair mating [19]. The differences in egg microbiota composition between tanks were more noticeable, but this is not surprising given that the eggs had derived from distinct parental matings and the water microbiota likely differed between tanks. Still, given that Tanks 1 and 2 effectively shared water by being in the same recirculation system, and therefore the constituent microbiota, it is surprising that the bacterial communities of the eggs at Day 0 from these tanks were not more similar to each other than compared to the egg microbiota from Tank 3. Furthermore, the bacterial communities in the samples from the different tanks diverged further to become even more dissimilar from each other during incubation in the common holding tank between Day 0 and Day 5. This was unexpected given that the eggs for 5 days had shared the same water, and thus been exposed to the same bacterial community in the water, meaning that the egg communities might have been expected to become more similar, particularly if the water community exerted an important influence over the egg community, but this was not the case. Taken together, these observations suggest that the rearing environment (i.e. the water) has a lesser role on the egg microbiota than parental or host effects (e.g. direct inheritance of a microbiota, or the presence/absence of factors on or in the egg influencing the microbiota that is able to establish) [40]. This hypothesis requires further investigation but, if confirmed, it indicates that significant gains could be achieved through a deeper grasp of the microbial status of broodstock and mechanisms that may allow beneficial microbes to be passed to the offspring. The variability at Day 5 between egg batches is interesting because other studies reported the microbiota to be diverse at early-life stages before stabilising ultimately during development [32, 35, 36, 41]. Nevertheless, it remains to be determined how the composition of the ballan wrasse egg microbiota affects the microbiota at later-life stages, or how the early microbiota influences the phenotype of the developing individual. The observed composition changes could play a role in inter-individual variations in marine fish microbiota reported elsewhere (e.g. Uren Webster et al. [33]) and it is tempting to speculate that such divergence, possibly exacerbated by disinfection, could underlie egg batch variability in survival and development of phenotypic traits and plasticity already linked to the microbiota in other species [9, 32].

The 5-day incubation led to differential effects between tanks on relative abundances of Vibrionaceae, which contain several important fish pathogenic species. Ultimately, the purpose of egg disinfection at commercial hatcheries is to reduce microbial abundance, particularly of opportunistic pathogens, in an effort to improve embryo survival [7]. Fujimoto et al. [42] reported that lake sturgeon (Acipenser fulvescens, Rafinesque, 1817) eggs incubated in stream water treated with ultraviolet light and filtration showed greater survival and developed distinct bacterial communities from those incubated in untreated water. While impacts of disinfection on egg survival and the abundances of culturable bacteria were not assessed in this present study, it did show that the response of the bacterial community to disinfection was not uniform (i.e. the effects on the eggs derived from different tanks were distinct but consistent across replicates), even when the eggs were incubated in a common environment. As such, definitions of egg disinfection based on culturable microbial abundance do not fully describe the true dynamics of the microbial community changes that the present approach managed to capture. Further, the data generated in this present study were sufficiently powerful to allow the detection of selected fish pathogenic bacterial species; however, the low abundances of reads corresponding to these pathogens prohibit a firm conclusion as to whether the disinfection protocol eliminated these bacteria from the eggs, though the pathogens were detected in fewer egg samples at Day 5 than at Day 0 (Table 2). Such experiments relying on $16 S$ rRNA gene detection and culture could determine the effect of different disinfection protocols on particular pathogens of interest. Given that mass DNA sequencing methodologies are becoming increasingly affordable, their application within hatcheries is now feasible as a screening and/or diagnostic method to monitor microbiota stability and identify when community shifts occur that might be detrimental for production.

This present study suffers the same limitations as other studies relying on non-culture methods in that it is not possible to determine whether the $16 S \mathrm{rRNA}$ gene sequences were derived from viable or metabolically active bacteria, while the PCR steps can also introduce some bias prior to sequencing [43]. Moreover, the primers used mean that mainly bacterial members of the egg microbiota were sampled herein 
and other microorganisms, such as eukaryotes and archaea, likely play important roles in the egg microbiota and also warrant attention [16]. The ability to describe the microbiota is an important initial step towards understanding the role of this community in the developing organism and to uncovering the functions that particular microbial species serve. As such, this present study is constrained by knowledge on these fundamental aspects of microbiota role and function, particularly in fish, though the data generated within are available publicly for re-analysis as new knowledge accumulates. Furthermore, the analyses herein were on relative abundance data and no attempt was made to quantify the bacteria in each sample, though a previous study found that the abundance of culturable bacteria changed little during 6 days of incubation under similar conditions at the same hatchery at $c a \cdot 10^{4} \mathrm{CFU}$ per egg [44]. Follow-up studies will examine the effect on the egg microbiota of different hatchery sites and fish species, while variations observed in the bacterial communities between tanks in the present study deserve closer attention to determine the relative contribution of the tank environment (i.e. water) compared to parental transfer, which was not possible to establish fully herein. Moreover, ballan wrasse are benthic substrate spawners and the eggs are coated in a protective gum layer to ensure these adhere to the substrate upon which they are spawned [45]. In hatcheries, this gum layer containing microorganisms can be removed to enable bio-secure transfer of eggs between farming sites. Removal of the gum layer liberates the eggs from the spawning mats that have a high-organic loading and, once free, it is believed removal of the gum will increase efficacy of disinfection by separating the eggs and increasing contact with the disinfectant. However, the gum layer may play a significant role in determining microbiota composition and stability. In support of this, the DNA yield extracted from a subset of eggs exposed to enzymatic degumming was insufficient to allow the $16 S$ rRNA gene analyses described above (data not shown), indicating it to be the gum layer that contains the majority of the bacteria associated with the egg. Follow up experiments with eggs of other commercially important finfish species are needed to understand all possible drivers of microbiota community change in response to disinfection.

In conclusion, this is the first study to describe comprehensively the bacterial community associated with ballan wrasse eggs and once the eggs had undergone a 5-day incubation in a commercial hatchery. Few studies have investigated the microbiota of marine fish eggs, despite the potential importance of this community on the phenotype of the fish $[8,9,35]$. Further knowledge in this field may advance the efficiency of ballan wrasse culture and prove useful as diagnostic markers of egg health and, in the fullness of time, it may be possible to manipulate the egg microbiota beneficially to influence later-life traits, including improved health and welfare, disease resistance, growth rate, feed conversion and nutritional properties.

Acknowledgements Special thanks to Paul Featherstone and Lindsay Sheriff (MOWI Scotland, Machrihanish) for assistance with sample collection. This research was supported in part by collaborative funding from the Scottish Aquaculture Innovation Centre and project partners MOWI Scotland, Scottish Seafarms Ltd and BioMar.

Author Contributions Conceived the study: AD and APD; performed the experiments: $\mathrm{AB}, \mathrm{AP}$ and $\mathrm{SM}$; designed the experiments: $\mathrm{MB}, \mathrm{AD}$ and APD; analysed the data: MB, AD and APD; wrote the first draft of the manuscript: $\mathrm{AB}$ and $\mathrm{APD}$; edited and improved the manuscript: $\mathrm{MB}, \mathrm{AP}, \mathrm{SM}, \mathrm{AA}$ and $\mathrm{AD}$; approved the final version: all authors.

\section{Compliance with Ethical Standards}

Conflicts of interest The authors declare no conflicts of interest.

Ethical Approval This study was approved by the University of Stirling Animal Welfare and Ethical Review Body. Best practice guidelines on the use of cleaner fish can be found here: https://www.scottishaq uaculture.com/media/1470/fhf-cleanerfish-guidelines.pdf (Accessed 28/08/2020).

Open Access This article is licensed under a Creative Commons Attribution 4.0 International License, which permits use, sharing, adaptation, distribution and reproduction in any medium or format, as long as you give appropriate credit to the original author(s) and the source, provide a link to the Creative Commons licence, and indicate if changes were made. The images or other third party material in this article are included in the article's Creative Commons licence, unless indicated otherwise in a credit line to the material. If material is not included in the article's Creative Commons licence and your intended use is not permitted by statutory regulation or exceeds the permitted use, you will need to obtain permission directly from the copyright holder. To view a copy of this licence, visit http://creativecommons.org/licenses/by/4.0/.

\section{References}

1. Skiftesvik AB, Bejelland RM, Durif CMF, Johansen IS, Browman HI (2013) Delousing of Atlantic salmon (Salmo salar) by cultured vs. wild ballan wrasse (Labrus bergylta). Aquaculture 402-403:113-118

2. Leclercq E, Davie A, Migaud H (2014) Delousing efficiency of farmed ballan wrasse (Labrus bergylta) against Lepeophtheirus salmonis infecting Atlantic salmon (Salmo salar) post-smolts. Pest Manag Sci 70:1274-1282

3. Bolton-Warberg M (2018) An overview of cleaner fish use in Ireland. J Fish Dis 41:1-5

4. Brooker AJ, Papadopoulou A, Gutierrez C, Rey S, Davie A, Migaud H (2018) Sustainable production and use of cleaner fish for the biological control of sea lice: recent advances and current challenges. Veterinary Record 183:383

5. Munro LA, Wallace IS (2017) Scottish Fish Farm Production Survey 2016. Scottish Government, Edinburgh, September 2017. Available at: https://www.gov.scot/publications/scottish-fish-farmproduction-survey-2016/. Accessed 01 Mar 2020

6. EcoFish (2012) EcoFish Ballan Wrasse Project Technical Leaflet 02. Available at: http://eco-fish.org/uploads/PDdownloads/ECOFI 
SH_leaflet2_Egg_Production_web-version1.pdf. Accessed 01 Mar 2020

7. De Swaef E, Van den Broeck W, Dierckens K, Decostere A (2016) Disinfection of teleost eggs: a review. Rev Aquac 8:321-341

8. Olafsen JA (2001) Interactions between fish larvae and bacteria in marine aquaculture. Aquaculture 200:223-247

9. Llewellyn MS, Boutin S, Hoseinifar SH, Derome N (2014) Teleost microbiomes: the state of the art in their characterization, manipulation and importance in aquaculture and fisheries. Front Microbiol 5:207

10. Thaiss CA, Zmora N, Levy M, Elinav E (2016) The microbiome and innate immunity. Nature 535:65-74

11. Butt RL, Volkoff H (2019) Gut microbiota and energy homeostasis in fish. Front Endocrinol 10:9

12. Vadstein O, Attramadal KJ, Bakke I, Forberg T, Olsen Y, Verdegem M, Giatsis C, Skjermo J, Aasen IM, Gatesoupe FJ, Dierckens $\mathrm{K}$, Sorgeloos P, Bossier P (2018) Managing the microbial community of marine fish larvae: a holistic perspective for larviculture. Front Microbiol 9:1820

13. de Bruijn I, Liu Y, Wiegertjes GF, Raaijmakers JM (2017) Exploring fish microbial communities to mitigate emerging diseases in aquaculture. FEMS Microbiol Ecol 94:fix161

14. Hansen GH, Olafsen JA (1989) Bacterial colonization of cod (Gadus morhua L.) and halibut (Hippoglossus hippoglossus) eggs in marine aquaculture. Appl Environ Microbiol 55:1435-1446

15. Egerton S, Culloty S, Whooley J, Stanton C, Ross RP (2018) The gut microbiota of marine fish. Front Microbiol 9:873

16. Liu Y, De Bruijn I, Jack AL, Drynan K, Van den Berg AH, Thoen E (2014) Deciphering microbial landscapes of fish eggs to mitigate emerging diseases. ISME J 8:2002-2014

17. Wang J, Jia H (2016) Metagenome-wide association studies: finemining the microbiome. Nat Rev Microbiol 14:508-522

18. Brugman S, Ikeda-Ohtsubo W, Braber S, Folkerts G, Pieterse CMJ, Bakker PAHM (2018) A comparative review on microbiota manipulation: lessons from fish, plants, livestock, and human research. Front Nutr 5:80

19. Grant B, Davie A, Taggart JB, Selly S, Picchi N, Bradley C, Prodohl P, Leclercq E, Migaud H (2016) Seasonal changes in broodstock spawning performance and egg quality in Ballan wrasse (Labrus bergylta). Aquaculture 464:505-514

20. Illumina (2016) 16S Metagenomic Sequencing Library Preparation Available at: https://support.illumina.com/documents/docum entation/chemistry_documentation/16s/16s-metagenomic-libraryprep-guide-15044223-b.pdf. Accessed 17 Jan 2019

21. Illumina (2016) Nextera Low Plex Pooling Guidelines. Available at: https://www.illumina.com/documents/products/technotes/techn ote_nextera_low_plex_pooling_guidelines.pdf. Accessed 17 Jan 2019

22. Schloss PD, Westcott SL, Ryabin T, Hall JR, Hartmann M, Hollister EB, Lesniewski RA, Oakley BB, Parks DH, Robinson CJ, Sahl JW, Stres B, Thallinger GG, Van Horn DJ, Weber CF (2009) Introducing mothur: open-source, platform-independent, community-supported software for describing and comparing microbial communities. Appl Environ Microbiol 75:7537-7541

23. Schloss PD (2013) Secondary structure improves OTU assignments of 16S rRNA gene sequences. ISME J 7:457-460

24. Quast C, Pruesse E, Yilmaz P, Gerken J, Schweer T, Yarza P, Peplies J, Glöckner FO (2013) The SILVA ribosomal RNA gene database project: improved data processing and web-based tools. Nucleic Acids Res 41:D590-596

25. Rognes T, Flouri T, Nichols B, Quince C, Mahé F (2016) VSEARCH: a versatile open source tool for metagenomics. PeerJ 4:e2584

26. McMurdie PJ, Holmes S (2014) Waste not, want not: why rarefying microbiome data is inadmissible. PLoS Comput Biol 10:e1003531
27. Oksanen J, Blanchet FG, Friendly M, Kindt R, Legendre P, McGlinn D, Minchin PR, O'Hara RB, Simpson GL, Solymos P, Stevens MHH, Szoecs E, Wagner H (2018) Vegan: Community Ecology Package. Available at: https://cran.r-project.org/web/ packages/vegan/vegan.pdf. Accessed 01 Mar 2020

28. R Core Team (2018) R: a language and environment for statistical computing. R Foundation for Statistical Computing, Vienna. Available at: https://www.R-project.org. Accessed 01 Mar 2020

29. Kendall MG (1938) A new measure of rank correlation. Biometrika 30:81-93

30. Benjamini Y, Hochberg Y (1995) Controlling the false discovery rate: a practical and powerful approach to multiple testing. J Roy Stat Soc: Ser B (Methodol) 57:289-300

31. Welch BL (1947) The generalization of "Student's" problem when several different population variances are involved. Biometrika 34:28-35

32. Wang AR, Ran C, Ring $\varnothing \mathrm{E}$, Zhou ZG (2018) Progress in fish gastrointestinal microbiota research. Rev Aquac 10:626-640

33. Uren Webster TM, Consuegra S, Hitchings M, Garcia de Leaniz C (2018) Interpopulation variation in the Atlantic salmon microbiome reflects environmental and genetic diversity. Appl Environ Microbiol 84:e00691-e718

34. Lokesh J, Kiron V, Sipkema D, Fernandes JMO, Moum T (2018) Succession of embryonic and the intestinal bacterial communities of Atlantic salmon (Salmo salar) reveals stage-specific microbial signatures. MicrobiologyOpen 13:e00672

35. Nikouli E, Meziti A, Antonopoulou E, Mente E, Kormas KA (2019) Host-associated bacterial succession during the early embryonic stages and first feeding in farmed gilthead sea bream (Sparus aurata). Genes 10:483

36. Romero J, Navarrete P (2006) 16S rDNA-based analysis of dominant bacterial populations associated with early life stages of coho salmon (Oncorhynchus kisutch). Microb Ecol 51:422-430

37. Wilkins LGE, Rogivue A, Schütz F, Fumagalli L, Wedekind C (2015) Increased diversity of egg-associated bacteria on brown trout (Salmo trutta) at elevated temperatures. Sci Rep 5:17084

38. Verner-Jeffreys DW, Shields RJ, Bricknell IR, Birkbeck TH (2004) Effects of different water treatment methods and antibiotic addition on larval survival and gut microflora development in Atlantic halibut (Hippoglossus hippoglossus L.) yolk-sac larvae. Aquaculture 232:129-143

39. Barker GA, Smith SN, Bromage NR (1990) Effect of oxolinic acid on bacterial flora and hatching success rate of rainbow trout, Oncorhynchus mykiss, eggs. Aquaculture 91:205-222

40. Nyholm SV (2020) In the beginning: egg-microbe interactions and consequences for animal hosts. Philos Trans Royal Soc B 375:20190593

41. Llewellyn MS, McGinnity P, Dionne M, Letourneau J, Thonier F, Carvalho G, Creer S, Derome N (2016) The biogeography of the Atlantic salmon (Salmo salar) gut microbiome. ISME J 10:1280-1284

42. Fujimoto M, Marsh TL, Scribner KT (in press) Effects of water filtration and temperature on microbial colonization and survival of lake sturgeon eggs. N Am J Aquac

43. Fouhy F, Clooney AG, Stanton C, Claesson MJ (2016) 16S rRNA gene sequencing of mock microbial populations- impact of DNA extraction method, primer choice and sequencing platform. BMC Microbiol 16:12

44. Papadopoulou A (2020) Health screening and autogenous vaccination strategies for atypical Aeromonas salmonicida in farmed ballan wrasse (Labrus bergylta, Ascanius). PhD thesis, University of Stirling

45. Grant B, Picchi N, Davie A, Leclercq E, Migaud H (2016) Removal of the adhesive gum layer surrounding naturally fertilised ballan wrasse (Labrus bergylta) eggs. Aquaculture 456:44-49 
Publisher's Note Springer Nature remains neutral with regard to jurisdictional claims in published maps and institutional affiliations. 